\title{
Olefin Metathesis with Ruthenium-Carbene Supported on Iron Oxide
}

Polymer-Supported Synthesis

\section{Key words}

carbenes

iron oxide

olefin metathesis

ruthenium
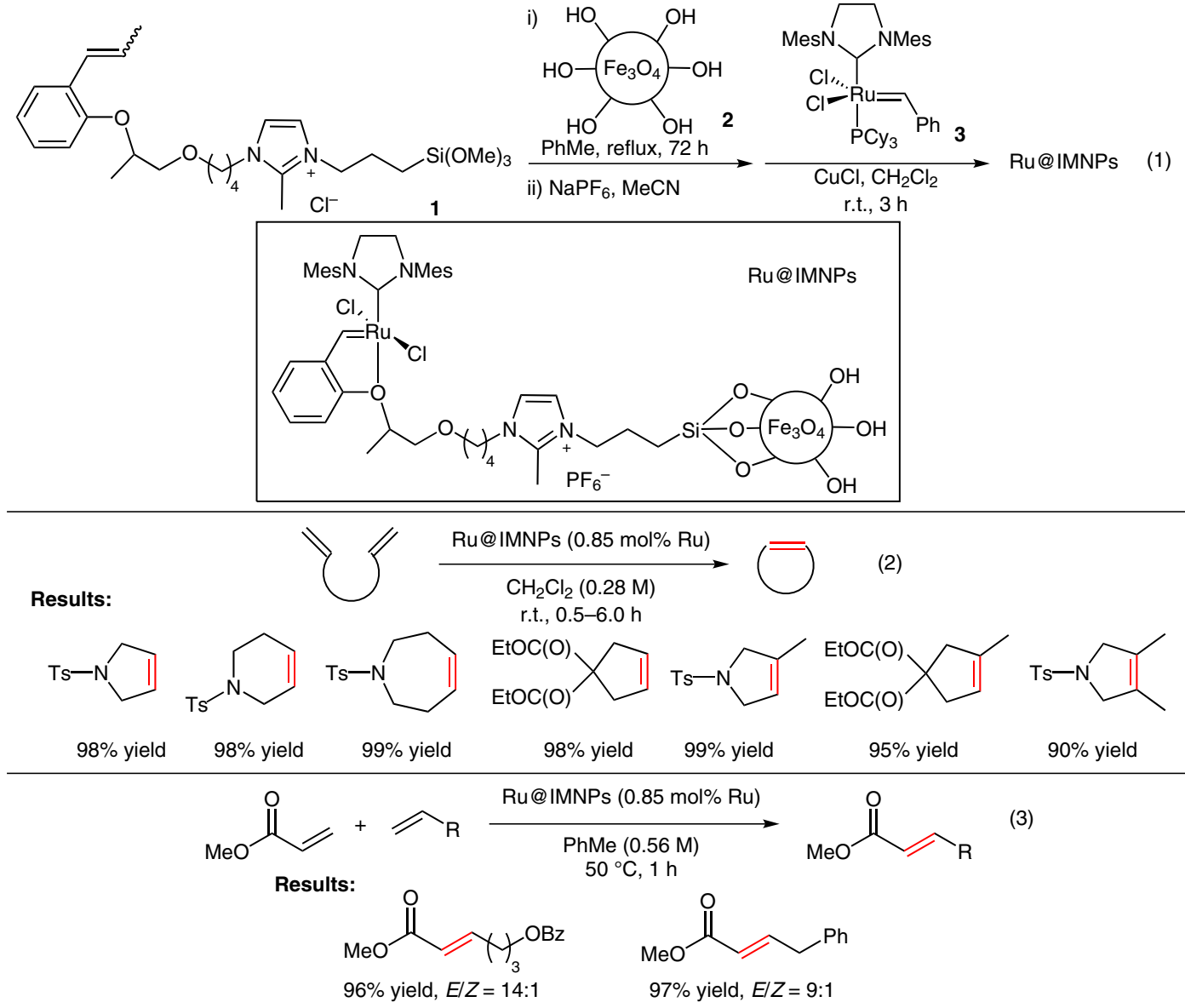

Significance: The Grubbs-Hoveyda rutheniumcarbene complex supported on ionic magnetic nanoparticles (Ru@IMNPs) was prepared by immobilization of imidazolium chloride 1 onto $\mathrm{Fe}_{3} \mathrm{O}_{4}$ 2, anion exchange with $\mathrm{NaPF}_{6}$, and metathesis with ruthenium complex 3 (eq. 1). Ru@IMNPs catalyzed the ring-closing metathesis of dienes to give the corresponding cyclic olefins in 90-99\% yield (eq. 2). The cross-metathesis of methyl acrylate with olefins using Ru@IMNPs also proceeded with high E-selectivity (eq. 3).
Comment: In the ring-closing metathesis of $\mathrm{N}, \mathrm{N}$ diallyl tosylamide, the catalyst was recovered magnetically and reused five times without significant loss of catalytic activity $\left(6^{\text {th }}\right.$ run: $96 \%$ conversion), although ICP-MS analysis showed significant leaching of the ruthenium species into the product (a loss of $54 \%$ of the ruthenium content of the fresh catalyst) during the initial three runs of the recycling experiment.

SYNFACTS Contributors: Yasuhiro Uozumi, Takao Osako

Synfacts 2015, 11(1), 0103 Published online: 15.12.2014

Dol: 10.1055/s-0034-1379713; Reg-No.: Y14314SF 